\title{
AMERICAN SECTION
}

As heretofore, Miss Mary L. Fleddérus and Miss Mary v. Kleeck will act as editors to the Social-Economic Section. During the war these ladies have made extensive researches in the domain of social-economics, the results of which have been summarized in the article hereunder. Regarding the section under their care, they hold the opinion that it should cover an entirely new field, which they indicate as the field of "Industrial sociology". Many special studies on social-economic subjects might converge upon it.

Already in 1939 these editors had promised moreover to bring our readers into contact with well-known American scientists in other branches of science fitting into the frame of our journal, a promise which is now going to be fulfilled.

\section{$* * *$}

\section{INTRODUCTION}

It may readily be understood how great is our pleasure and satisfaction that present circumstances permit the reappearance of so valuable a periodical as Synthese, and the opening of this section on social and economic subject matter, to which we are most willing to contribute, whenever possible and appropriate.

In this connection, it would appear that a beginning might be made in breaching the past period of separation and isolation by offering to Synthese a summary of a basic study made during the past years by ourselves in the Department of Industrial Studies of the Russell Sage Foundation in New York. This study constitutes an inquiry into the changing technological basis of society. It is intended to illustrate the progress of present-day productivity and its consequences in the prevailing social economic environment. While limited to the United States, it may, likewise, serve as a frame of reference for other nations, whatever the stage of their industrial development. As the foreword states:

"The new science which has evolved during the past hundred years, with discoveries greatly accelerated in the last fifty years, would have made a period covering several centuries notable for scientific progress. The rapidity of the resulting rate of change explains in part the inability of society to adjust itself to the new basis for livelihood. Understanding of the process of adjustment requires not only analysis of social consequences of scientific discoveries, but recognition of technology itself as a prime mover in social change. No minor adjustment to a single invention will suffice. Technology must be analyzed in its entirety as setting new tasks of social organization for every nation, and for the whole world. No investigator working alone can adequately assemble all the needed facts nor weave the pattern of the 
future from the present tangled skein. A total analysis needs to be based upon contributions from specialists in all relevant fields."

Synthese therefore may well be the proper medium for including in its pages, from time to time, reference to this continuing study of some of the most basic questions of our time.

\author{
Mary van Kleeck, \\ Director of Industrial Studies, \\ Russell Sage Foundation \\ Chairman, Research Group, \\ International Industrial \\ Relations Institute \\ Mary L. Fleddérus \\ Director, International Industrial \\ Relations Institute; Research \\ Associate, Department of Industrial \\ Studies, Russell Sage Foundation
}

\title{
TECHNOLOGY AND LIVELIHOOD
}

The decade inaugurated by the memorable year 1929 witnessed the phenomenon of unprecedented unemployment and inadequate standards of living for large sections of the population, coexistent with greatly increased industrial (including agrarian) productivity, resulting from new science and invention. Such a situation would appear to constitute a new and great challenge to society to utilize this new productivity for livelihood and living standards.

Following this decade, the year 1939 saw the beginning of war in Europe and defense preparations in the United States. Many of the unemployed were absorbed in the military forces. The needs of the situation, mereover, suddenly called for all available and potential production for the manifold purposes of war. Co-ordination of scientific knowledge and synchronization of production methods were required in a total but elastic production plan, at the service of the armed forces and their strategy. Thus our high-powered production apparatus came to be guided by a unifying aim, a guiding motive absent from our peacetime economy.

Nevertheless, also in peacetime the new technology, by its very nature, increasingly makes these same demands for co-ordination and adjustment toward an agreed and socially desirable end. Society has as yet failed to adjust itself to the new basis for security of livelihood. Livelihood is the living won by work. The new technology in itself is setting new tasks of organization of life and labor in the local community, the nation, and the entire globe.

The present inquiry makes use of significant information accumu- 